\title{
Enteric methane production in lactating dairy cows with continuous feeding of essential oils or rotational feeding of essential oils and lauric acid
}

\author{
G. Klop, ${ }^{*}$ J. Dijkstra, ${ }^{* 1}$ K. Dieho, ${ }^{*}$ W. H. Hendriks, ${ }^{*}$ and A. Bannink† \\ ${ }^{*}$ Animal Nutrition Group, and \\ †Animal Nutrition, Wageningen Livestock Research, Wageningen University and Research, PO Box 338, 6700 AH Wageningen, the Netherlands
}

\begin{abstract}
Rumen microbes can adapt to feed additives, which may make the decrease in enteric $\mathrm{CH}_{4}$ production upon feeding an additive a transient response only. This study investigated alternate feeding of $2 \mathrm{CH}_{4}$ mitigating feed additives with a different mode of action on persistency of lowering $\mathrm{CH}_{4}$ production compared with feeding a single additive over a period of $10 \mathrm{wk}$. Four pairs of cows were selected, and within pairs, cows were randomly assigned to either the control (AR-AR) or the alternating (AR-LA) concentrate treatment. The AR concentrate contained a blend of essential oils (Agolin Ruminant, Agolin SA, Bière, Switzerland; 0.17 $\mathrm{g} / \mathrm{kg}$ of dry matter) and the LA concentrate contained lauric acid (C12:0; $65 \mathrm{~g} / \mathrm{kg}$ of dry matter). A basal concentrate without Agolin Ruminant and lauric acid was fed during the pretreatment period (2 wk). Thereafter, the cows assigned to the AR-AR treatment received the AR concentrate during all 10 treatment weeks (5 periods of 2 wk each), whereas cows assigned to the AR-LA treatment received $\mathrm{AR}$ and $\mathrm{LA}$ concentrates rotated on a weekly basis. Methane emission was measured in climate respiration chambers during periods 1,3 , and 5. From period 3 onward, dry matter intake and milk protein concentration were reduced with the AR-LA treatment. Milk fat concentration was not affected, but the proportion of C12:0 in milk fat increased upon feeding C12:0. Molar proportions of acetate and propionate in rumen fluid were lower and higher, respectively, with the AR-LA than with the AR-AR treatment. Methane yield $(\mathrm{g} / \mathrm{kg}$ of dry matter intake) and intensity ( $\mathrm{g} /$ $\mathrm{kg}$ of fat- and protein-corrected milk yield) were not affected by treatment. Methane yield and intensity were significantly lower (12 and $11 \%$, respectively) in period 1 compared with the pretreatment period, but no significant difference relative to pretreatment period was observed in period 3 (numerically 9 and
\end{abstract}

Received September 23, 2016.

Accepted January 3, 2017.

${ }^{1}$ Corresponding author: jan.dijkstra@wur.nl
$7 \%$ lower, respectively) and in period 5 (numerically 8 and $4 \%$ lower, respectively). Results indicate a transient decrease in $\mathrm{CH}_{4}$ yield and intensity in time, but no improvement in extent or persistency of the decline in $\mathrm{CH}_{4}$ due to rotational feeding of essential oils and C12:0 in lactating dairy cows.

Key words: methane, lauric acid, essential oils, dairy cow

\section{INTRODUCTION}

The mitigating effect of feed additives supplemented to dairy cow diets on enteric $\mathrm{CH}_{4}$ emission may be a transient effect if rumen microbes adapt to these additives. Guan et al. (2006) compared the effect of feeding a single ionophore (monensin) with feeding a rotation of ionophores (monensin and lasalocid) on enteric $\mathrm{CH}_{4}$ production in Angus steers. The size and duration of the decrease in $\mathrm{CH}_{4}$ production did not differ between the 2 ionophore treatments, and the mitigating effect disappeared after several weeks. The absence of an effect is probably a result of the similar mode of action of both ionophores, which may be overcome if several additives with different mode of action are rotated.

In agronomy, herbicide rotations are applied as a strategy to prevent or delay herbicide resistance of weeds (Beckie, 2006). In broilers, shuttle programs with 2 or more anticoccidial compounds, usually with different modes of action, are widely used to reduce resistance of these protozoa (Chapman, 2001). YáñezRuiz et al. (2016) reviewed the use of in vitro batch culture technique to assess enteric $\mathrm{CH}_{4}$ production, and recommended use of inoculum from animals that have been adapted to the treatment for at least 2 wk. Klop et al. (2017) evaluated the adaptation of dairy cows to feed additives with different modes of action in vivo [namely, lauric acid (C12:0; LA) and Agolin Ruminant (AR; commercial blend of essential oils, with eugenol, geranyl acetate, and coriander oil being the main components; Agolin SA, Bière, Switzerland)] using the in vitro gas production technique. Klop et al. (2017) reported a shift toward a higher propionate proportion 
at the expense of acetate when in vitro $\mathrm{CH}_{4}$ production was reduced by $\mathrm{AR}$, whereas it is known that $\mathrm{C} 12: 0$ can have strong antibacterial and antimethanogenic effects (Hristov et al., 2011; Zhou et al., 2013). Results indicated a transient effect of $\mathrm{AR}$ on in vitro $\mathrm{CH}_{4}$ production, with $\mathrm{CH}_{4}$ production being lowered after $8 \mathrm{~d}$ of feeding the additive to the donor cows, whereas after 15 and $22 \mathrm{~d}$, in vitro $\mathrm{CH}_{4}$ production did not differ anymore from the control treatment. In contrast, a persistent mitigating effect on in vitro $\mathrm{CH}_{4}$ production was observed when donor cows were fed LA.

Based on these findings, it was hypothesized that continuous feeding of AR would result in a transient decrease of $\mathrm{CH}_{4}$ emission, whereas weekly rotation of $\mathrm{AR}$ and $\mathrm{C} 12: 0$ would result in a persistent $\mathrm{CH}_{4}$ decline. Therefore, the aim of the present study was to compare the extent and duration of changes in $\mathrm{CH}_{4}$ emission and in performance of dairy cows receiving either AR only or AR and C12:0 using a weekly rotation schedule.

\section{MATERIALS AND METHODS}

\section{Experimental Design, Animals, and Housing}

All experimental procedures were approved by the Animal Care and Use Committee of Wageningen University (Wageningen, the Netherlands). Four pairs of cows (4 primiparous and 4 multiparous; $139 \pm 38$ DIM and $610 \pm 59 \mathrm{~kg}$ of BW at the start of the experimental period; mean $\pm \mathrm{SD}$ ), of which 4 cows were fitted with a permanent rumen cannula $(10 \mathrm{~cm}$ i.d., Type $1 \mathrm{C}$, Bar Diamond Inc., Parma, ID) were included in the experiment. Cows were paired based on parity, lactation stage, milk production, and presence or absence of a rumen fistula. Within pairs, cows were randomly assigned to either the control (AR-AR) or the alternating (AR-LA) concentrate treatment with a total treatment length of $10 \mathrm{wk}$ ( 5 periods of $2 \mathrm{wk}$ each). The treatments were preceded by an 11-d pretreatment period. In the pretreatment period, cows were housed in tie-stalls and fed the basal diet without experimental feed additives. Thereafter, cows were individually housed in climate respiration chambers (CRC) for a period of $2.5 \mathrm{~d}$ to measure $\mathrm{CH}_{4}$ emissions on the basal diet. Four individual CRC were available at the same time, and therefore, a staggered approach was taken with the first 2 pairs of cows (block A) starting $3 \mathrm{~d}$ earlier with the pretreatment period than the second 2 pairs of cows (block B). After their initial $\mathrm{CH}_{4}$ measurement in the CRC during the pretreatment period, block A cows returned to the tie-stalls and were fed the basal ration without additives for another $17 \mathrm{~d}$. During these $17 \mathrm{~d}$, block B cows were housed in CRC for their ini- tial 2.5-d $\mathrm{CH}_{4}$ measurements, followed by a treatment schedule of 2 wk in the CRC (period 1, period 3, period 5 ) with intermediate 2 -wk tie-stall periods (period 2, period 4). The same treatment schedule of 2 wk CRC or tie-stall housing was followed by cows in block $\mathrm{A}$ and block B, with cows from one block housed in the CRC (or tie-stall) while cows from the other block housed in the tie-stall (or CRC). For each 2-wk CRC period, cows entered the CRC at $1500 \mathrm{~h}$ and left around $0900 \mathrm{~h}$ on d 15. Days 2 to 7 and 9 to 14 were used to collect $\mathrm{CH}_{4}$ data. The CRC were cleaned in the mornings of $\mathrm{d} 1$ (before entrance of the cows) and d 8. Rotation (AR to LA or vice versa) occurred in the mornings of $d 2$ and 9.

A detailed description of the CRC design and gas measurements was reported by van Gastelen et al. (2015). Briefly, in each CRC (volume $35 \mathrm{~m}^{3}$ ), relative humidity was maintained at $70 \%$ and temperature at $16^{\circ} \mathrm{C}$, and the ventilation rate in each compartment was $42 \mathrm{~m}^{3} / \mathrm{h}$. Inlet and exhaust air of each compartment was sampled at 10-min intervals. Gas concentrations and ventilation rates were corrected for pressure, temperature, and humidity to arrive at standard temperature pressure dew point volumes of inlet and exhaust air. Immediately before the experiment, compartments were checked by releasing known amounts of $\mathrm{CO}_{2}$ in each compartment and the measured recovery. The recovered amounts of $\mathrm{CO}_{2}$ were between 98 and $100 \%$. Cows were exposed to $16 \mathrm{~h}$ of light per day.

\section{Diets and Feeding}

A TMR with basal concentrate was fed during the pretreatment period. For the AR-AR treatment, the TMR with AR concentrate was fed during all 10 treatment weeks, whereas for the AR-LA treatment the AR and LA concentrates were rotated on a weekly basis (AR in wk 1 of each period, LA in wk 2 of each period). The AR concentrate contained Agolin Ruminant $(0.17 \mathrm{~g} / \mathrm{kg}$ of $\mathrm{DM})$ and the LA concentrate contained lauric acid (C12:0; $65 \mathrm{~g} / \mathrm{kg}$ of DM; $\geq 98 \%$ pure, SigmaAldrich, Zwijdrecht, the Netherlands) (Table 1). During the experimental period in the tie-stalls and CRC, animals were fed twice daily (at 0600 and $1600 \mathrm{~h}$ ). All cows received their experimental diet as a TMR, composed of $40 \%$ corn silage, $30 \%$ grass silage, and $30 \%$ concentrate on a DM basis (Table 2). Portions of the grass silage and corn silage mixture were weighed in crates twice weekly and stored at $6^{\circ} \mathrm{C}$. Concentrates were weighed separately for each cow and these were manually mixed with the roughage at the time of feeding. The external marker $\mathrm{Cr}_{2} \mathrm{O}_{3}(1.7 \mathrm{~g} / \mathrm{kg}$ of $\mathrm{DM})$ was added to the compound feed (Research Diet Services, Wijk bij Duurstede, the Netherlands) for estimation of 
Table 1. Ingredient composition $(\mathrm{g} / \mathrm{kg}$ of $\mathrm{DM})$ of the pretreatment concentrate (basal) and the treatment concentrates that contained either Agolin Ruminant (AR; Agolin SA, Bière, Switzerland) or lauric acid (LA) as a feed additive

\begin{tabular}{lrrr}
\hline & \multicolumn{3}{c}{ Concentrates } \\
\cline { 2 - 4 } Ingredient & Basal & AR & LA $^{1}$ \\
\hline Corn & 305 & 305 & 285 \\
Corn gluten feed & 143 & 143 & 133 \\
Soybean meal & 99 & 99 & 93 \\
Rapeseed meal & 93 & 93 & 87 \\
Formaldehyde-treated soybean meal & 85 & 85 & 79 \\
Sugar beet pulp & 78 & 78 & 73 \\
Palm kernel expeller & 73 & 73 & 68 \\
Formaldehyde-treated rapeseed meal & 57 & 57 & 53 \\
Sugar cane molasses & 34 & 34 & 32 \\
CaCO & 14 & 14 & 14 \\
Trace mineral and vitamin premix & 9.0 & 9.0 & 9.0 \\
NaCl & 4.1 & 4.1 & 4.1 \\
NaHCO & 2.8 & 2.8 & 2.8 \\
$\mathrm{MgO}_{3}$ & 1.7 & 1.7 & 1.7 \\
$\mathrm{Cr}_{2} \mathrm{O}_{3}$ & 1.7 & 1.7 & 1.7 \\
$\mathrm{Agolin}$ Ruminant & - & 0.17 & - \\
Lauric acid (C12:0) & - & - & 65 \\
\hline
\end{tabular}

${ }^{1}$ In the LA concentrate, ingredients were proportionally exchanged against $\mathrm{C} 12: 0$, except for the minerals and the vitamin and mineral premix, which were kept at the same level as in the other 2 concentrates.

apparent total-tract digestibility (ATTD). During the first $8 \mathrm{~d}$ of the pretreatment period, cows received the basal diet ad libitum. From d 9 onward, cows received their diet in amounts of $95 \%$ of the average daily intake of the cow with the lowest intake within a pair. This feed restriction was imposed throughout the remainder of the experiment in an effort to avoid confounding effects of DMI on $\mathrm{CH}_{4}$ production. Cows had free access to water throughout the experiment.

\section{Measurements, Sampling, and Laboratory Analyses}

Feed and Feces Samples. Representative samples of all individual TMR components were collected at the time of feed preparation. Fecal grab samples were collected in the respiration chambers for estimation of ATTD of nutrients. Fecal samples were collected at each milking during the last $4 \mathrm{~d}$ before the moment of concentrate switch. Samples were stored frozen $\left(-20^{\circ} \mathrm{C}\right)$ pending analysis. After thawing, samples were air-dried at $60^{\circ} \mathrm{C}$ until constant weight, and ground to pass a 1-mm screen (Wiley mill; Peppink 100AN, Olst, the Netherlands) before analysis. Dried samples were analyzed for DM, crude ash, N, NDF, ADF, ADL, starch, sugar, GE, and chromium. In fresh silage samples, $\mathrm{NH}_{3}$ was analyzed according to the methods described by Klop et al. (2016). Crude fat content of dried feed and feces samples was analyzed based on NEN-ISO 1735 (ISO, 2004). A modification to the standard procedure was that samples were hydrolyzed with hydrochloric acid at $75^{\circ} \mathrm{C}$ and subsequently the solution, containing hydrochloric acid and ethanol, was extracted with diethyl ether and petroleum ether. Solvents were removed by distillation before the mass of the extracted material was determined.

Orts were quantitatively collected and weighed daily during the period in the respiration chambers. If the amount consisted of more than $4 \%$ of DM supply, a representative subsample was analyzed for DM, ash,

Table 2. Average analyzed chemical composition of TMR ingredients [corn silage, grass silage, pretreatment concentrate (basal), and treatment concentrates that contained either Agolin Ruminant (AR; Agolin SA, Bière, Switzerland) or lauric acid (LA) as a feed additive] and the calculated composition of the complete TMR ( $\mathrm{g} / \mathrm{kg}$ of DM, unless stated otherwise)

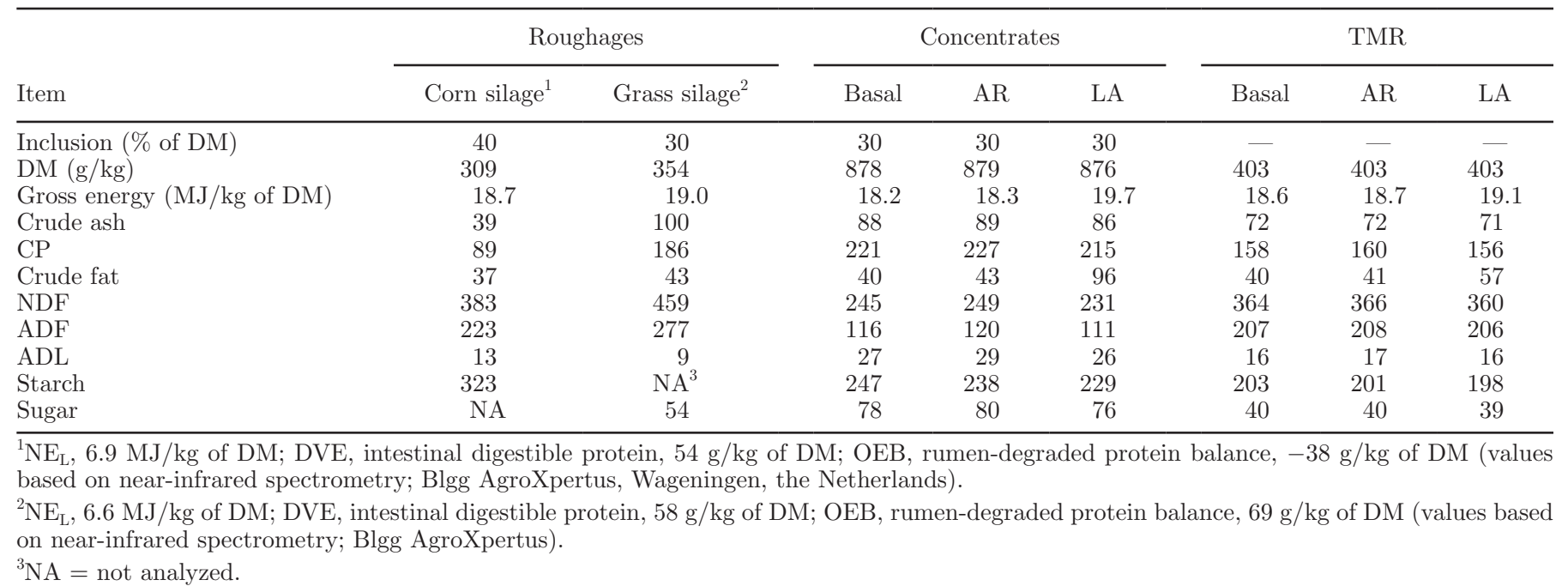


and crude fat content according to the same methods as the feed samples.

Milk Production and Milk Composition. Cows were milked twice daily (at 0600 and $1600 \mathrm{~h}$ ) throughout the experiment. Milk production was recorded at each milking. For all cows, a subsample of milk from each milking in the CRC was analyzed for fat, protein, lactose, and urea content according to methods described by Hatew et al. (2015). Average milk composition for each cow was calculated from the weighted average of all samples taken during the measurement period in the CRC. Separate samples were collected for analysis of milk fatty acid (FA) profile through gas chromatography as detailed by van Gastelen et al. (2015). Fat- and protein-corrected milk yield (FPCM) was calculated according to the formula: FPCM $(\mathrm{kg} / \mathrm{d})=(0.337+$ $0.116 \times$ fat $\%+0.06 \times$ protein $\%) \times$ milk yield $(\mathrm{kg} / \mathrm{d})$ (CVB, 2008).

Rumen Content Samples. During each of the tie-stall periods (period 2 and 4), rumen fluid samples were collected from the cannulated cows at the day of concentrate switch and the day thereafter (i.e., d 1, 2, 8 , and 9 of each of the two 2 -wk periods). Samples were collected at $0 \mathrm{~h}$ (just before), and at 1, 2, 3, 4, 6, 8, and $10 \mathrm{~h}$ after morning feeding on both days. Rumen fluid samples were collected in 3 equal amounts from the front and middle of the ventral sac and from the cranial sac of the rumen. In each sample, $\mathrm{pH}$ was measured immediately after sampling, without filtering, using a portable $\mathrm{pH}$ meter (HI 99141, Hannah instruments, IJsselstein, the Netherlands). A $600-\mu \mathrm{L}$ aliquot of rumen fluid was mixed with an equal volume of orthophosphoric acid, containing iso-caproic acid as internal standard and stored at $-20^{\circ} \mathrm{C}$. After thawing, samples were centrifuged for $10 \mathrm{~min}$ at $10,000 \times g$ at $4^{\circ} \mathrm{C}$. Separation of VFA was achieved by gas chromatography (Fisons HRGC Mega 2, CE Instruments, Milan, Italy) with $\mathrm{H}_{2}$ as the carrier gas as detailed by Dieho et al. (2016).

\section{Statistical Analysis}

All data were analyzed using PROC MIXED (SAS version 9.2, SAS Institute Inc., Cary, NC). For one cow (AR-LA treatment), data from the pretreatment period were excluded, because of a sudden large drop in milk production, while maintaining feed intake. No clinical signs of disease were observed and milk yield increased again during the following $2 \mathrm{wk}$ in the tie-stalls. Data for $\mathrm{CH}_{4}$ emission, intake, milk production, milk composition, and ATTD all relate to the CRC periods. Period averages were calculated for each cow. Data from days that cows entered the chambers and from days that the chambers were cleaned were not included in the analyses. The pretreatment period included 2 full days of data, and each CRC period included 12 full days of data.

The 2 pairs of cows that went into the CRC at the same time throughout the experiment were considered as one block. The following time points were included in the analyses: pretreatment (background measurement), period 1 (first 2 wk of dietary treatment), period 3 (wk 5 and 6 of dietary treatment), and period 5 (wk 9 and 10 of dietary treatment). The model contained block, treatment, time (= period), and treatment $\times$ time interaction as fixed effects. Repeated measures over time for each cow $\times$ treatment combination were taken into account using a first order autoregressive $[\mathrm{AR}(1)]$ covariance structure.

Rumen data from 2 sampling days were pooled before statistical analysis. One cow (AR-LA treatment) had access to other feed than the treatment feed allocated to her on the last rumen sampling day of period 4. Therefore, the values of this day were not used to calculate average values for this cow. Rumen data were analyzed using a model with fixed effects of treatment, time $(=$ period $)$, hour, and treatment $\times$ time and treatment $\times$ hour. Cow $\times$ time was included as random effect with repeated measurements for each time(cow) combination included, and a spatial power covariance structure was fitted because of unequal time intervals between sampling hours. In all statistical analyses, denominator degrees of freedom were estimated using the Kenward-Roger option. Pairwise comparisons of treatment means were evaluated using the Tukey-Kramer method. In case of significant interaction terms, between-treatment comparisons for each period, or within-treatment comparisons over periods were made using a SLICE statement and $P$-values were corrected using the Tukey-Kramer method. Results are reported as least squares means, and significance of effects was declared at $P \leq 0.05$ and trends at $0.05<P$ $\leq 0.10$.

\section{RESULTS AND DISCUSSION}

\section{DMI, Milk Production, and Milk Composition}

The main aim of this study was to evaluate the effect of alternate feeding of $2 \mathrm{CH}_{4}$-mitigating feed additives (AR and C12:0; AR-LA treatment) with a different mode of action, compared with feeding a single additive (AR only; AR-AR treatment), on $\mathrm{CH}_{4}$ emission and performance of dairy cows. Dry matter intake of AR-AR cows did not differ between the pretreatment and treatment periods. In contrast, despite the restricted feeding regimen, DMI of AR-LA was significantly reduced from period 3 onward (Table 3). In comparison to C14:0 
and C18:0 supplementation, C12:0 supplementation decreases feed intake (Dohme et al., 2004). In line with the present results, Külling et al. (2002) also observed a reduction in DMI upon supplementation with $\mathrm{C} 12: 0$. If the palatability of C12:0 is the main reason for the reduced DMI (Külling et al., 2002), encapsulation of the product could provide a solution to avoid reductions in intake. Another possible reason for decreased intake upon C12:0 supplementation is impaired ruminal degradation of fiber (Dohme et al., 2001). The latter will increase the retention time of feed in the rumen, which may affect DMI.

Milk production was not affected by treatment, but was decreased in period 5 as cows were advancing in lactation. During periods 3 and 5, but not during the pretreatment period and period 1, milk protein concentration was reduced in the AR-LA treatment, which resulted in a treatment $\times$ time interaction. Feeding digestible lipid in significant amounts is generally known to reduce the concentration of protein in milk (Walker et al., 2004; Rabiee et al., 2012), but in the present experiment dietary lipid content only increased by 16 $\mathrm{g} / \mathrm{kg}$ of DM. The periods of reduced milk protein content correspond to the periods that AR-LA cows had a reduced DMI. With ME intake being lower, protein intake was also lower, which might have been more limiting for milk protein production than for milk production in kilograms per day. Milk urea N content was not affected by treatment, time, or their interaction.

Milk fat depression following C12:0 supplementation has been reported previously (Hristov et al., 2011; Faciola and Broderick, 2014; Klop et al., 2017). Although in the present study milk fat concentration was numerically lower in periods 3 and 5 with AR-LA, there was no treatment effect on milk fat concentration (Table 3). Santos et al. (2010) reported increased milk fat content and production when cows were fed AR $(0.85 \mathrm{~g} / \mathrm{cow}$ per d) and suggested that this could be the result of an increased acetate:propionate $(\mathbf{A}: \mathbf{P})$ ratio in the rumen (which was not measured). However, the cows in their study produced $49 \mathrm{~kg}$ of milk/d with an average DMI of $26 \mathrm{~kg} /$ cow per d, which is higher than in the present experiment. A transient shift toward a larger proportion of propionate was observed in vitro using rumen fluid from cows on a diet containing AR (Klop et al., 2017). As the control cows in the study of Santos et al. (2010) had a numerically higher DMI and a similar milk production level, a plausible explanation for the increased milk fat concentration upon feeding $\mathrm{AR}$ is increased body fat mobilization rather than a shift in VFA profile, with the mobilized FA used by the mammary gland for milk fat synthesis (Chilliard et al., 2000).

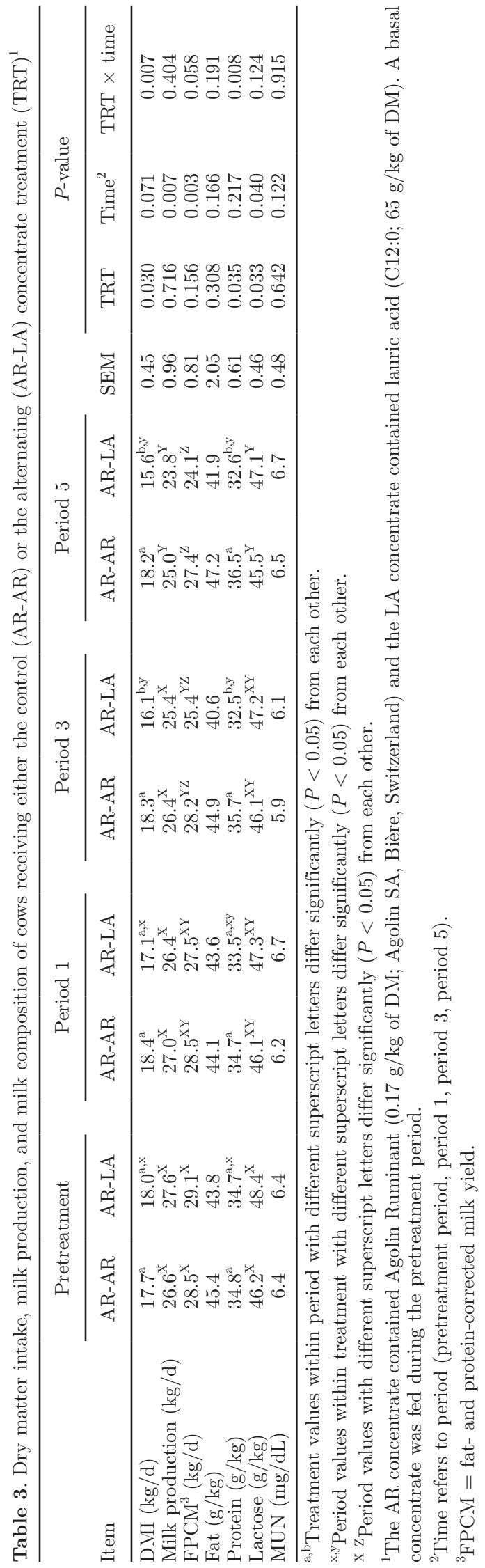

Journal of Dairy Science Vol. 100 No. 5, 2017 
The proportion of C12:0 in milk fat of cows on the AR-LA treatment was higher than for AR-AR (Table 4 ), in particular in period 1 . The DMI of these cows was only reduced from period 3 onward, which may explain that the largest proportion of $\mathrm{C} 12: 0$ in milk fat was observed in period 1. Dohme et al. (2004) observed a higher proportion of C12:0 in milk fat upon supplementing the diet with C12:0 compared with C14:0 and C18:0. van Zijderveld et al. (2011) also observed an elevated proportion of $\mathrm{C} 12: 0$ in milk fat and a lower proportion of C16:0 upon feeding a mixture of additives including $\mathrm{C} 12: 0$. The increased proportion of $\mathrm{C} 12: 0$ and the reduced proportion of C16:0 in milk fat of AR-LA cows in period 1 is in line with findings of Hristov et al. (2011), who supplemented dairy cows with $240 \mathrm{~g} / \mathrm{d}$ of either stearic acid (C18:0; control treatment), C12:0, or myristic acid (C14:0). They also reported larger proportions of trans C18:1 (C18:1 trans-6-8, C18:1 trans-9, C18:1 trans-10, C18:1 trans-11) and CLA isomers in milk of cows on a C12:0 treatment than in cows on a C18:0 or C14:0 treatment, which are often associated with milk fat depression. In the study by Dohme et al. (2004), C18:1 trans FA were not higher with C12:0, but C18:1 cis FA were. The proportion of SFA was only reduced upon C12:0 supplementation in the study of Hristov et al. (2011). In period 1 of the present study, when intake of $\mathrm{C} 12: 0$ was highest, proportions of several C18:1 FA were increased in the AR-LA treatment but not in the AR-AR treatment, resulting in a significant treatment $\times$ time interaction (Table 4 ). The proportion of SFA was not affected by treatment. Only a tendency for a treatment $\times$ time interaction was observed, with SFA being lower in the AR-LA treatment during the treatment periods compared with the pretreatment period, and opposite to changes between periods in SFA proportions with the AR-AR treatment.

Benchaar et al. (2007) evaluated the effect of a mixture of essential oil compounds (Crina ruminants; including thymol, eugenol, vanillin, guaiacol, and limonene) in dairy cattle and did not find any effect on milk FA profile. To our knowledge, the effect of AR on milk FA profile has not been reported previously. In both AR-AR and AR-LA, the proportions of C15:0 iso and $\mathrm{C} 15: 0$ anteiso were reduced in period 1 compared with the pretreatment period (Table 4). Castro Montoya et al. (2011) reported a positive relationship between iso $\mathrm{FA}$ and calculated $\mathrm{CH}_{4}$ production $(\mathrm{mmol} / \mathrm{mol}$ of VFA). Fibrolytic bacteria are generally enriched in iso FA, whereas amylolytic bacteria contain high amounts of linear odd-chain FA and anteiso FA (Vlaeminck et al., 2006). Hence, a positive relation between $\mathrm{CH}_{4}$ emission and iso FA can be assumed, as well as a negative relation between $\mathrm{CH}_{4}$ emission and linear odd-chain FA and anteiso FA (reviewed by van Gastelen and Dijk-

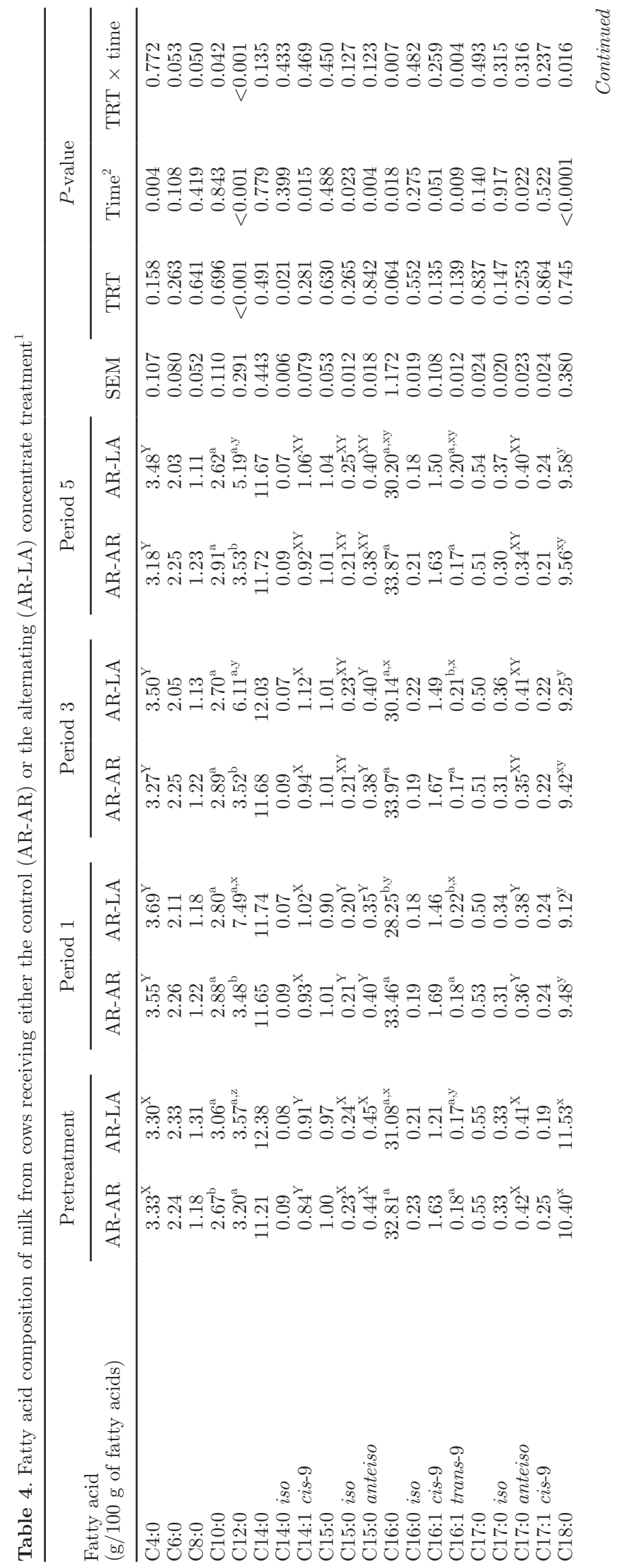




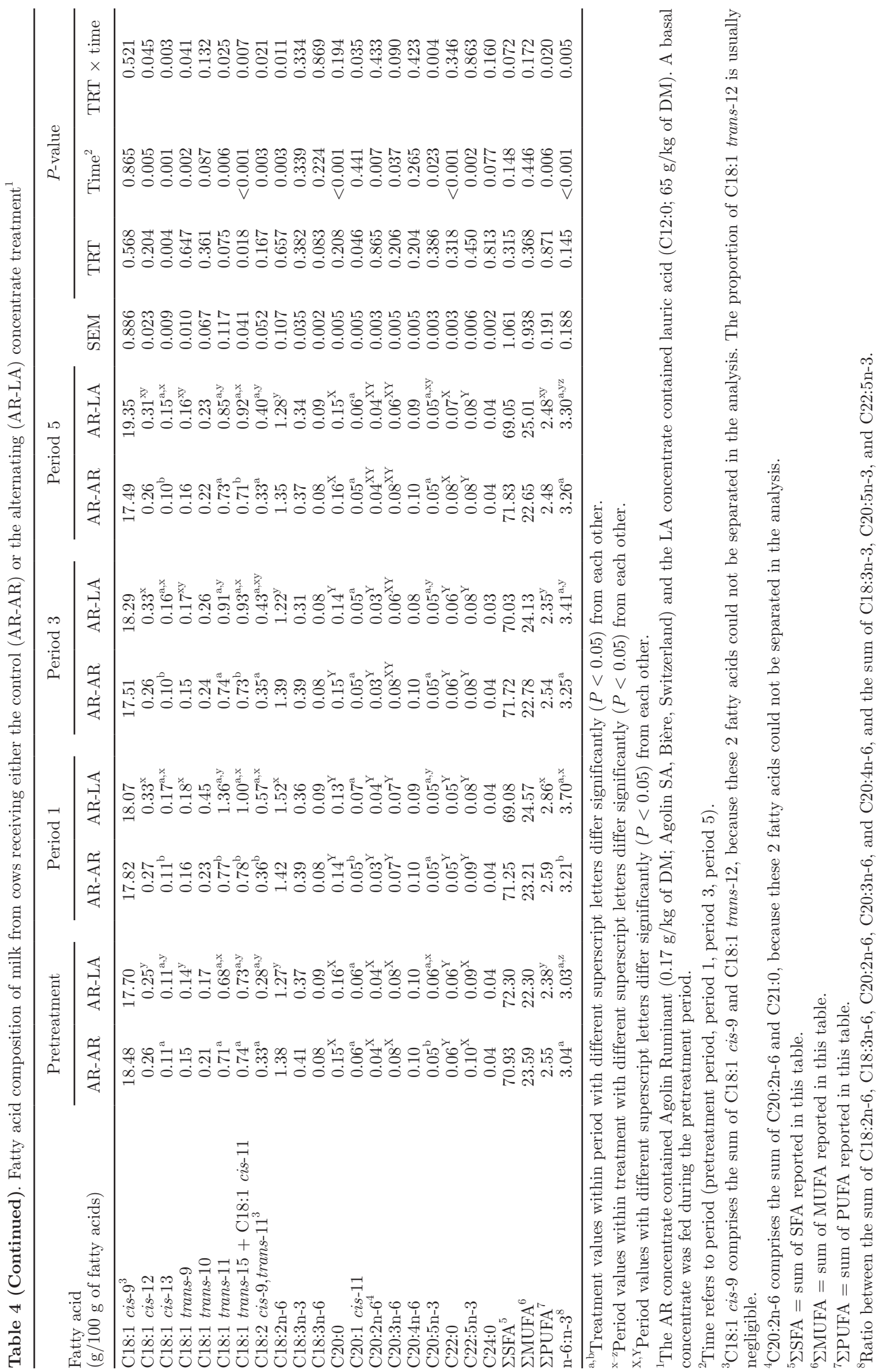




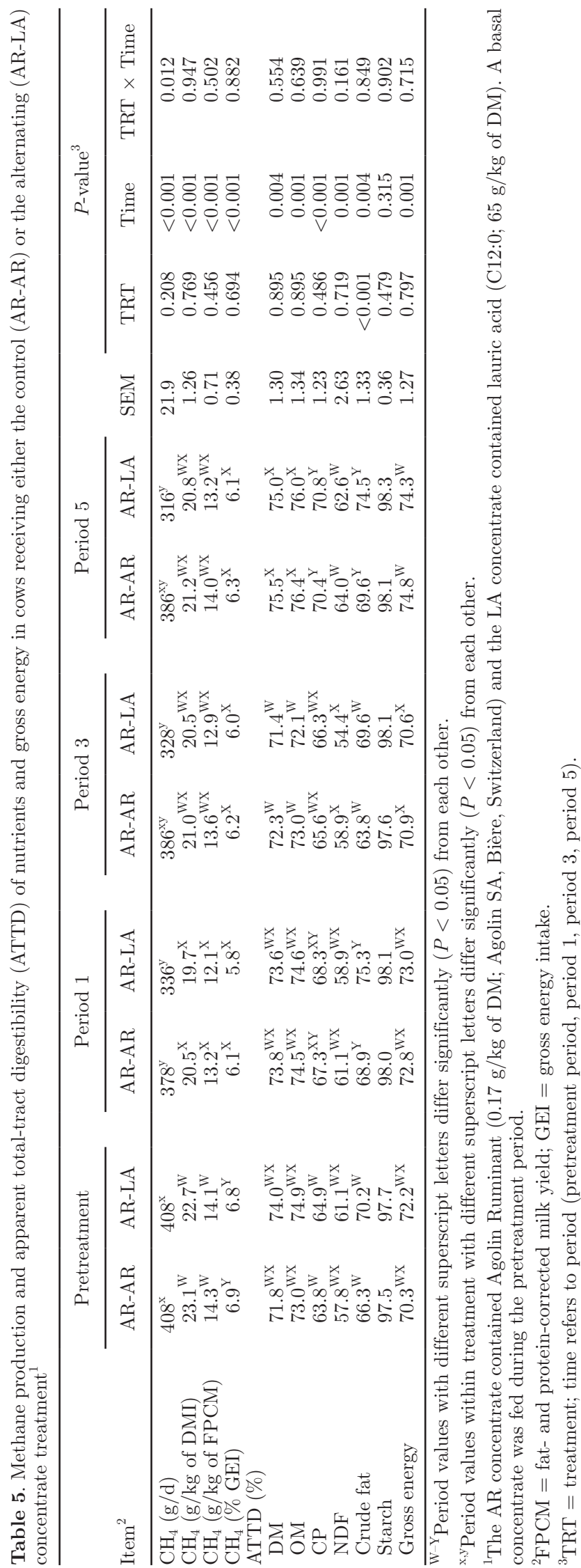

stra, 2016). During period 1 , in line with the change in $\mathrm{C} 15: 0$ iso, $\mathrm{C} 15: 0$ anteiso, and $\mathrm{C} 17: 0$ anteiso content of milk fat, $\mathrm{CH}_{4}$ yield was indeed lower than during the pretreatment period (Table 5). Within the AR-AR treatment, the proportion of C18:0 in milk fat was also reduced in period 1 compared with the pretreatment period (Table 4). In several studies, milk C18:0 is not related to $\mathrm{CH}_{4}$ production (van Gastelen and Dijkstra, 2016), but decreases toward the end of a lactation cycle (Stoop et al., 2009). Overall, AR does not seem to have caused major shifts in the milk FA profile.

\section{Methane Emission}

A significant treatment $\times$ time interaction was observed for $\mathrm{CH}_{4}$ production (g/d; Table 5). Methane production with AR-AR in period 1 was lower than in the pretreatment period ( $7 \%$ lower), but in period 3 and 5 did not differ with the pretreatment period (5\% lower; numerically only). However, with the ARLA treatment, methane production in periods 1,3 , and 5 was significantly lower (on average 20\%) than in the pretreatment period. The reduced DMI in period 3 and 5 with the AR-LA treatment but not with the AR-AR treatment offers an explanation for the treatment $\times$ time interaction that was observed for $\mathrm{CH}_{4}$ production. Both $\mathrm{CH}_{4}$ yield $\left(\mathrm{g} / \mathrm{kg}\right.$ of DMI) and $\mathrm{CH}_{4}$ intensity $(\mathrm{g} / \mathrm{kg}$ of FPCM) changed over time, but were not affected by treatment. Methane yield and intensity were significantly lower (12 and $11 \%$, respectively) in period 1 compared with the pretreatment period, but no significant difference relative to pretreatment period was observed in period 3 (numerically 9 and $7 \%$ lower, respectively) and in period 5 (numerically 8 and $4 \%$ lower, respectively). It should be noted that evaluating $\mathrm{CH}_{4}$ intensity over time may be flawed because milk production declines after peak production, and this decline as such would lead to an increase $\mathrm{CH}_{4}$ intensity in time during the present experiment. The $\mathrm{CH}_{4}$ energy loss (expressed as a fraction of GE intake) was lower in the treatment periods compared with pretreatment period.

The results suggest that upon continuous feeding of $\mathrm{AR}$, the $\mathrm{CH}_{4}$-mitigating effect in the initial $2 \mathrm{wk}$ (period 1) is larger than from wk 5 onward (period 3), indicating adaptation to the blend of essential oils used. Furthermore, the absence of a more persistent decrease of $\mathrm{CH}_{4}$ yield and intensity with rotational feeding implies that this rotation did not prevent or retard adaptation. Overall, the weekly rotation of AR and C12:0 did not result in a persistently lower $\mathrm{CH}_{4}$ production compared with feeding AR only. However, using the same statistical model as for the complete data on only the pretreatment period and the weeks in which 


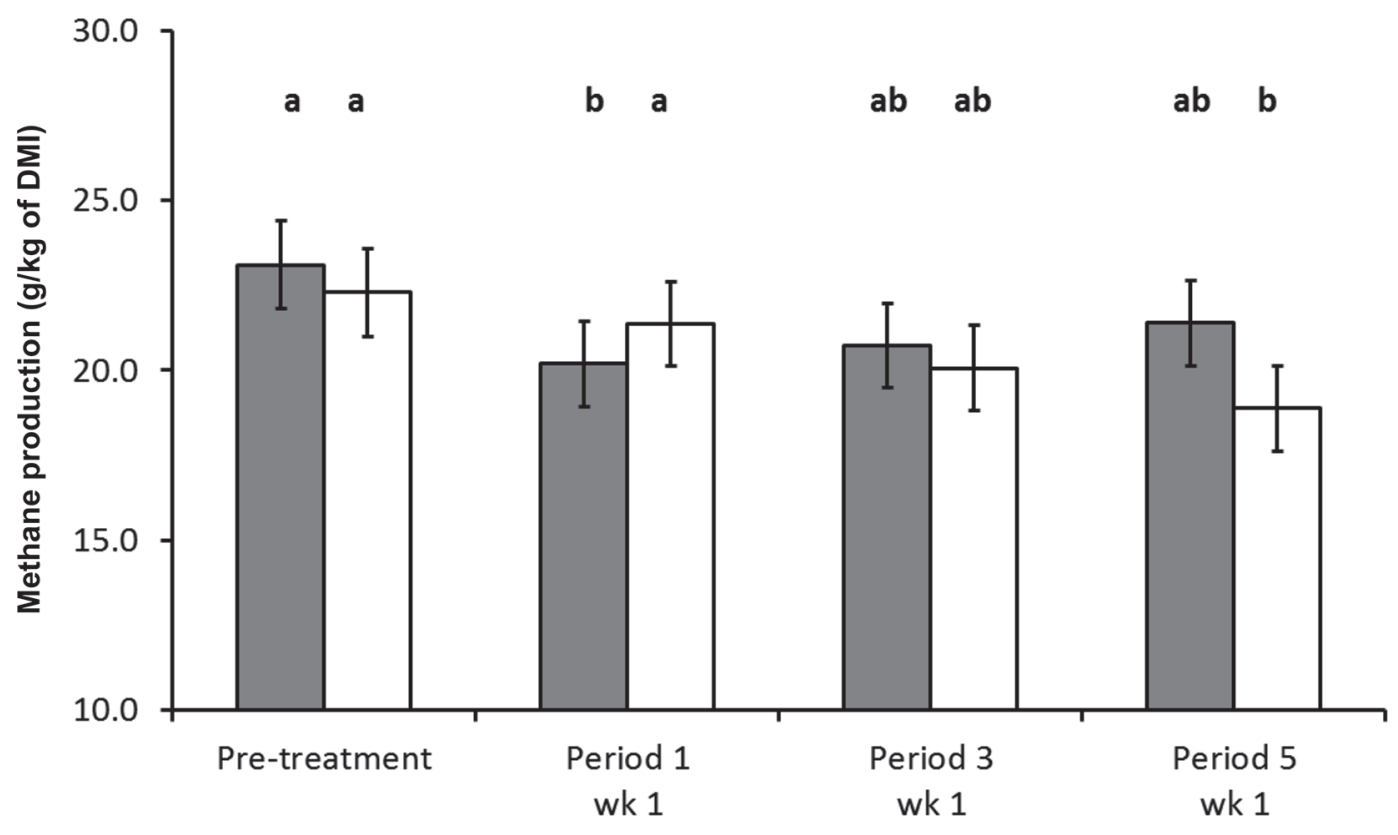

Figure 1. Methane production $(\mathrm{g} / \mathrm{kg}$ of $\mathrm{DMI})$ of cows $(\mathrm{n}=4$ per treatment) during the weeks in periods 1,3 , and 5 that both treatment groups received the AR concentrate, which contained Agolin Ruminant (0.17 g/ $\mathrm{kg}$ of DM; AGOLIN SA, Bière, Switzerland). The diet contained $30 \%$ concentrate on a DM basis. Gray bars represent the treatment group that received AR only for a period of 10 wk, and white bars represent the group that received AR and lauric acid $(\mathrm{C} 12: 0 ; 65 \mathrm{~g} / \mathrm{kg}$ of concentrate DM) following a weekly rotation schedule. Error bars represent SEM. Periods within treatment with different letters differ $(P<0.05)$.

AR was fed to both the AR-LA and AR treatment groups may also provide some further insight in the applicability of the concept of rotation as a mitigation strategy (Figure 1). The effect of treatment was not significant, but a significant effect of period and a significant treatment $\times$ period interaction was observed. In period 5 , but not in period 1 and 3 , feeding $A R$ in the AR-LA rotation treatment significantly reduced $\mathrm{CH}_{4}$ yield compared with the pretreatment period. This may indicate that alternate feeding of $\mathrm{C} 12: 0$ and $\mathrm{AR}$ does result in reduced $\mathrm{CH}_{4}$ yield in the week that $\mathrm{AR}$ is fed. However, it cannot be excluded that any carry-over effects of $\mathrm{C} 12: 0$ in the second week of the preceding period have affected the $\mathrm{CH}_{4}$ yield upon feeding $\mathrm{AR}$ in the subsequent week. Nevertheless, the initial mitigating effect of $\mathrm{AR}$ seems to be repeatable after a week of feeding C12:0. In a previous experiment (Klop et al., 2017), in which rumen fluid was collected as inoculum from donor cows fed $\mathrm{AR}$, in vitro $\mathrm{CH}_{4}$ production was decreased $8 \mathrm{~d}$ after introduction of the additive to the donor cow diet, but no effect was observed after 15 and $21 \mathrm{~d}$. In the same study, feeding C12:0 to donor cows showed a persistent decrease in $\mathrm{CH}_{4}$ production in vitro. Based on these in vitro results, in the present experiment we evaluated the hypothesis that in vivo, the AR-AR treatment would result in a transient drop of $\mathrm{CH}_{4}$ production, whereas AR-LA would decrease $\mathrm{CH}_{4}$ more persistently. In their review of in vitro batch culture systems, Yáñez-Ruiz et al. (2016) made several recommendations related to potential differences in microbial profile and adaptation, including using the same donor animals as the target species, choosing diets and incubation substrates with similar nutrient composition, adapting donor animals to the experimental diet before rumen fluid collection, rumen fluid collection before morning feeding, and applying a restricted feeding regimen to obtain a better interpretation of in vitro data for the in vivo situation. In the experiment described by Klop et al. (2017), many of those criteria were met; nevertheless, the hypothesis based on these vitro results could not be confirmed based on results of the present study.

Castro-Montoya et al. (2015) supplemented a similar dose of AR ( $1 \mathrm{~g} /$ cow per $\mathrm{d})$ as used in the present study to a diet composed of grass silage $(460 \mathrm{~g} / \mathrm{kg}$ of DM), corn silage $(370 \mathrm{~g} / \mathrm{kg}$ of DM), soybean meal $(50 \mathrm{~g} / \mathrm{kg}$ of $\mathrm{DM})$, and concentrates $(120 \mathrm{~g} / \mathrm{kg}$ of DM) for $6 \mathrm{wk}$. In their experiment, $\mathrm{AR}$ tended to persistently lessen $\mathrm{CH}_{4}$ production and $\mathrm{CH}_{4}$ yield by 15 and $14 \%$ on average, respectively, in wk 6 after first introduction, whereas $\mathrm{CH}_{4}$ intensity was not affected. The overall average $\mathrm{CH}_{4}$ production of $247 \mathrm{~g} / \mathrm{d}$ and $15.8 \mathrm{~g} / \mathrm{kg}$ of DMI during the weeks that AR was fed was lower than in the present study. Methane expressed per kilogram of milk was similar, because of a higher milk production of cows in the present study. Interestingly, in an experiment 


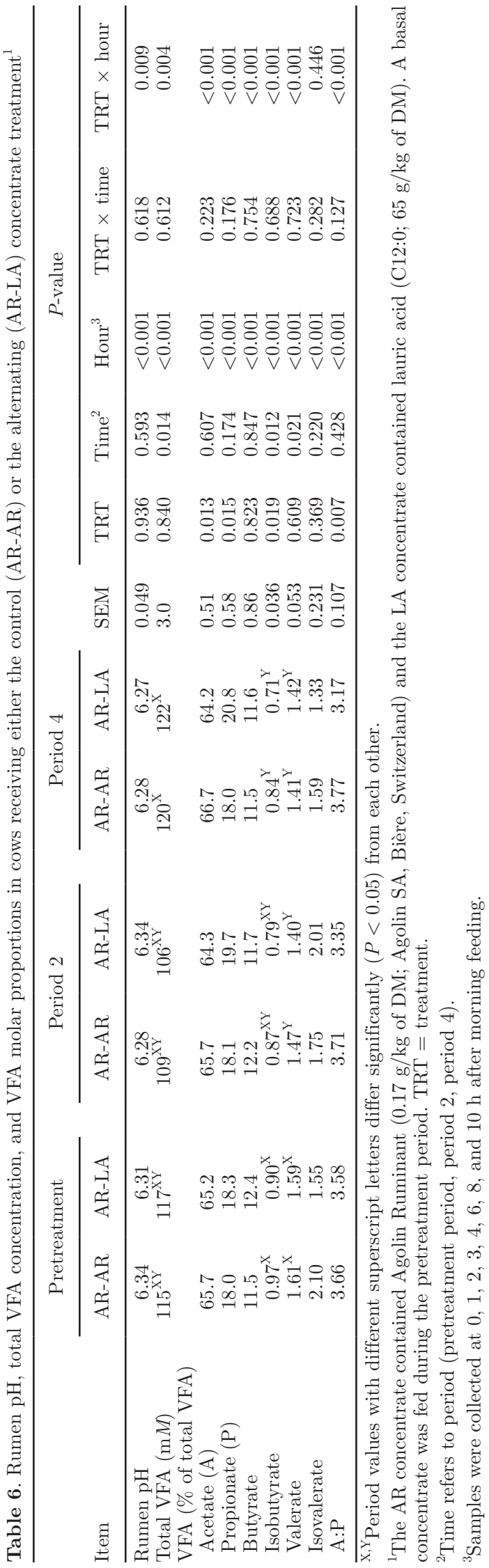

with beef cattle (Castro-Montoya et al., 2015), daily $\mathrm{CH}_{4}$ production and $\mathrm{CH}_{4}$ yield did not change upon AR supplementation in wk 2, 4, or 6 after introduction. van Zijderveld et al. (2011) found that feeding a mixture of additives (C12:0, C14:0, linseed oil, and calcium fumarate) decreased $\mathrm{CH}_{4}$ production and $\mathrm{CH}_{4}$ energy loss as a fraction of gross energy intake, but the additive mixture did not affect $\mathrm{CH}_{4}$ yield or intensity. In the study of Külling et al. (2002), the addition of C12:0 (40 $\mathrm{g} / \mathrm{kg}$ of $\mathrm{DM}$ ) reduced $\mathrm{DMI}, \mathrm{CH}_{4}$ production, and $\mathrm{CH}_{4}$ intensity (expressed in $\mathrm{g} / \mathrm{kg}$ of $\mathrm{ECM}$ ) compared with the C18:0 control diet. No effect was observed for $\mathrm{CH}_{4}$ yield. Martin et al. (2010) concluded that C12:0 and C14:0 have a more depressive effect on $\mathrm{CH}_{4}$ emission than other FA. However, Grainger and Beauchemin (2011) did not find any effect of type of FA (C12:0, C14:0, C18:1, C18:2, C18:3) on $\mathrm{CH}_{4}$ yield when total fat was restricted to $<80 \mathrm{~g} / \mathrm{kg}$ of DM. The present experiment had a dietary fat content of up to $57 \mathrm{~g} / \mathrm{kg}$ of DM and is within this range. In view of the transitory decline in $\mathrm{CH}_{4}$ yield and intensity with $\mathrm{AR}$, and given the negative effects of C12:0 on feed intake, it is worthwhile to investigate rotational feeding of AR in combination with another compound other than that used in the present study.

\section{Digestibility of Nutrients}

Apparent total-tract digestibility of nutrients was not affected by time $\times$ treatment interaction or treatment, except for crude fat (Table 5). The higher fat digestibility in AR-LA cows is most likely caused by the difference in fat content between the AR and LA concentrate (Table 2). If fat supplementation is higher, the apparent digestibility values are less affected by fecal excretion of endogenous fat sources (Kil et al., 2010). Faciola and Broderick (2014) reported that both ruminal and total-tract fiber digestion were depressed following C12:0 supplementation. In general, milk fat depression caused by intermediates of ruminal biohydrogenation may be associated with factors including low rumen $\mathrm{pH}$ and reduced fiber degradation in the rumen (Bauman and Griinari, 2003). The absence of a treatment effect on NDF digestibility in the present study may explain why milk fat content was also not significantly affected with the AR-LA treatment. The period did significantly affect ATTD of most nutrients, with in general a lower digestibility in period 3 than in other periods. The reason for this lower digestibility is unknown.

\section{Rumen $\mathrm{pH}$ and VFA}

Average rumen $\mathrm{pH}$ and total VFA concentration were not affected by treatment or treatment $\times$ time 
interaction (Table 6). Molar proportions of acetate and propionate were lower and higher, respectively, in the AR-LA treatment compared with the AR-AR treatment, resulting in a significantly lower $\mathrm{A}: \mathrm{P}$ ratio with the AR-LA treatment. No treatment $\times$ time interaction was found for these parameters, but the numerical differences between AR-AR and AR-LA were larger during the treatment period than during the pretreatment period (Table 6), and in particular the numerical difference in the A:P ratio became larger with advanced period. Molar proportion of acetate in AR-LA was lower at 0,8 , and $10 \mathrm{~h}$ after a.m. feeding, and tended to be lower at $6 \mathrm{~h}$ after a.m. feeding compared with that in AR-AR (Figure 2). Faciola and Broderick (2014) reported reduced VFA concentrations (123 and $128 \mathrm{mM}$ for $\mathrm{C} 12: 0$ and control, respectively), and in line with the present results reported reduced molar proportion of acetate (63.7 and $65.0 \%$ of total VFA for C12:0 and control, respectively) following C12:0 supplementation. Rumen samples were collected at multiple time points relative to feeding, but only average values were reported.
In the present study, the molar proportion of propionate was higher in the AR-LA treatment than in the AR-AR treatment from $4 \mathrm{~h}$ postfeeding onward at the expense of acetate (Figure 2). Feeding C12:0 often reduces protozoa counts in rumen fluid (Hristov et al., 2011; Faciola and Broderick, 2014). Results from a meta-analysis by Eugène et al. (2004) indicated that defaunation results in a decreased molar proportion of acetate and butyrate, and an increased molar proportion of propionate in rumen fluid, which might be associated with less $\mathrm{CH}_{4}$ production. Impaired fiber degradation in the rumen may also cause a relative increase in propionate proportion. Apparent total-tract digestibility of NDF was not affected by additive treatment in this study, although values were numerically lower for ARLA than AR-AR during periods 1, 3, and 5 (Table 5). As discussed by van Zijderveld et al. (2011), a negative effect of a treatment on ruminal fiber degradation may be partly compensated by fermentation in the hindgut. The latter will yield less nutrients to support milk production than rumen degradation of fiber. On the other hand, it is probable that the lower DMI of the AR-LA

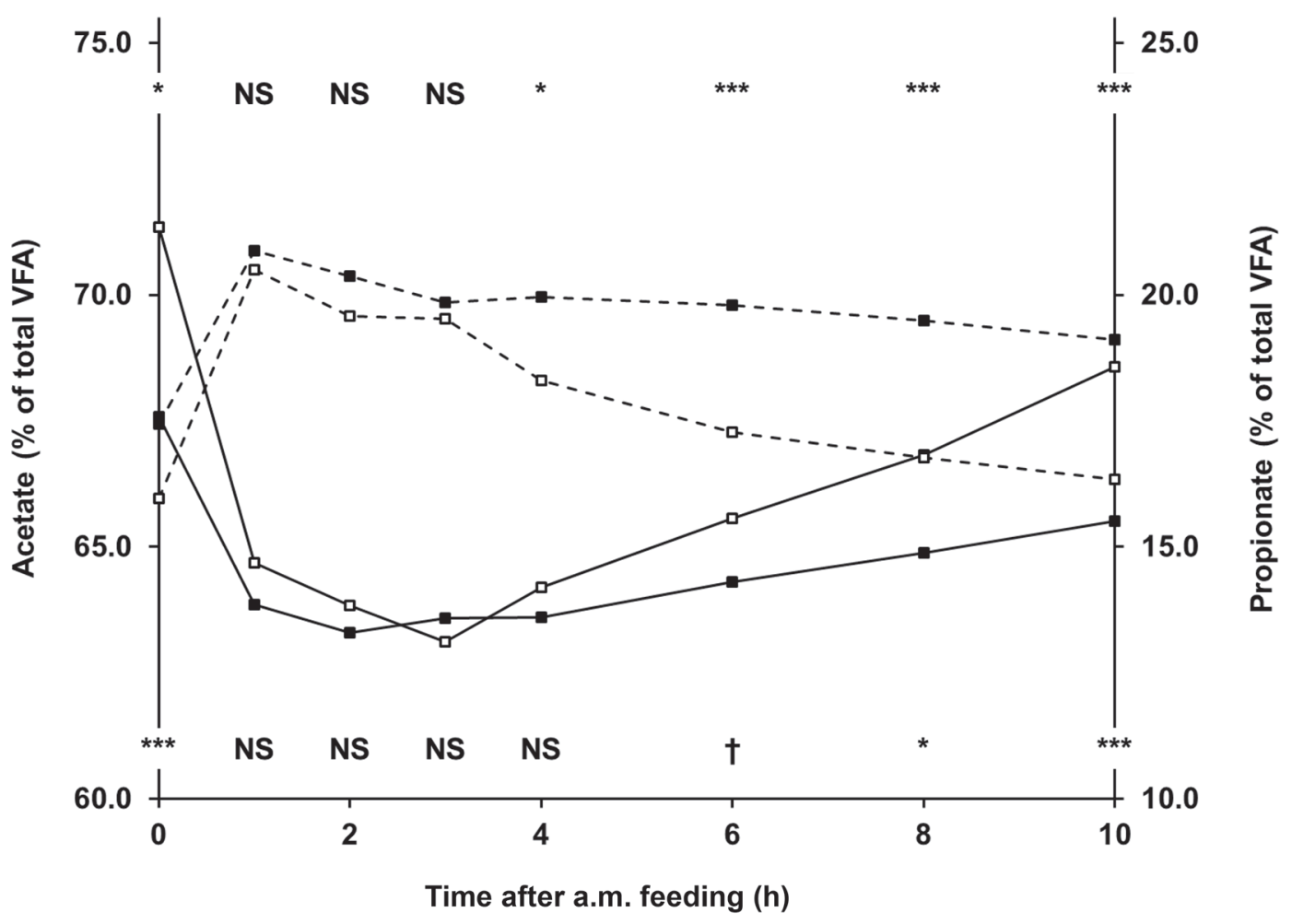

Figure 2. Molar percentage of acetate (solid lines) and propionate (dashed lines) in rumen fluid from cows after a.m. feeding of either the AR-AR treatment [Agolin Ruminant $(0.17 \mathrm{~g} / \mathrm{kg}$ of DM; Agolin SA, Bière, Switzerland; $\square ; \mathrm{n}=2)$ ] or the AR-LA treatment [weekly rotation of Agolin Ruminant $(0.17 \mathrm{~g} / \mathrm{kg}$ of DM) and lauric acid $(65 \mathrm{~g} / \mathrm{kg}$ of DM; $\mathbf{\square} ; \mathrm{n}=2)]$. Each data point represents the treatment average of the pretreatment period, period 2, and period 4 for the hours indicated. Symbols indicate significance of treatment differences at each time point $\left(\dagger 0.05<P \leq 0.10 ;{ }^{*} P \leq 0.05 ;{ }^{* * *} P \leq 0.001\right)$. The top row of symbols relates to propionate and the bottom row to acetate. Pooled SEM values were 0.44 and 0.43 for acetate and propionate, respectively. 
treatment in the present study resulted in longer rumen retention time of feed. This may have alleviated treatment effects on NDF digestibility.

\section{CONCLUSIONS}

In the present study, continuous feeding of $\mathrm{AR}$ as well as rotational feeding of $\mathrm{AR}$ and $\mathrm{C} 12: 0$ resulted in a transient decline in $\mathrm{CH}_{4}$ yield and intensity. The rotational feeding of $\mathrm{AR}$ and $\mathrm{C} 12: 0$ did not improve the extent and persistency of $\mathrm{CH}_{4}$ mitigation compared with AR only. Dietary levels of C12:0 appeared to be too high for application in practice, as DMI was reduced in the rotation treatment. Future research should clarify if rotational feeding of $\mathrm{CH}_{4}$-mitigating additives (with a transient effect) can result in a persistent mitigation effect.

\section{ACKNOWLEDGMENTS}

Stefan Regelink and Sanne Klerx (Wageningen University, Wageningen, the Netherlands) and the staff of the experimental facilities "Carus" are acknowledged for their assistance during the experiment. This study is part of the Low Emission Animal Feed project. Authors acknowledge financial support of the Dutch Ministry of Economic Affairs (The Hague, the Netherlands), Product Board Animal Feed (Zoetermeer, the Netherlands), and the Dutch Dairy Board (Zoetermeer, the Netherlands), and acknowledge the Top Institute (Wageningen, the Netherlands) Food and Nutrition project, "Reduced methane emission of dairy cows," for providing milk FA data.

\section{REFERENCES}

Bauman, D. E., and J. M. Griinari. 2003. Nutritional regulation of milk fat synthesis. Annu. Rev. Nutr. 23:203-227.

Beckie, H. J. 2006. Herbicide-resistant weeds: Management tactics and practices. Weed Technol. 20:793-814.

Benchaar, C., H. V. Petit, R. Berthiaume, D. R. Ouellet, J. Chiquette, and P. Y. Chouinard. 2007. Effects of essential oils on digestion, ruminal fermentation, rumen microbial populations, milk production, and milk composition in dairy cows fed alfalfa silage or corn silage. J. Dairy Sci. 90:886-897.

Castro Montoya, J., A. M. Bhagwat, N. Peiren, S. De Campeneere, B. De Baets, and V. Fievez. 2011. Relationships between odd- and branched-chain fatty acid profiles in milk and calculated enteric methane proportion for lactating dairy cattle. Anim. Feed Sci. Technol. 166:596-602.

Castro-Montoya, J., N. Peiren, J. W. Cone, B. Zweifel, V. Fievez, and S. De Campeneere. 2015. In vivo and in vitro effects of a blend of essential oils on rumen methane mitigation. Livest. Sci. 180:134-142.

Chapman, H. D. 2001. Use of anticoccidial drugs in broiler chickens in the USA: Analysis for the years 1995 to 1999. Poult. Sci. $80: 572-580$.

Chilliard, Y., A. Ferlay, R. M. Mansbridge, and M. Doreau. 2000. Ruminant milk fat plasticity: Nutritional control of saturated, polyunsaturated, trans and conjugated fatty acids. Ann. Zootech. 49:181-205.

CVB. 2008. CVB Table booklet feeding of ruminants. CVB series no. 43. Centraal Veevoederbureau, Lelystad, the Netherlands.

Dieho, K., J. Dijkstra, J. T. Schonewille, and A. Bannink. 2016. Changes in ruminal volatile fatty acid production and absorption rate during the dry period and early lactation as affected by rate of increase of concentrate allowance. J. Dairy Sci. 99:5370-5384.

Dohme, F., A. Machmüller, F. Sutter, and M. Kreuzer. 2004. Digestive and metabolic utilization of lauric, myristic and stearic acid in cows, and associated effects on milk fat quality. Arch. Anim. Nutr. 58:99-116.

Dohme, F., A. Machmüller, A. Wasserfallen, and M. Kreuzer. 2001. Ruminal methanogenesis as influenced by individual fatty acids supplemented to complete ruminant diets. Lett. Appl. Microbiol. $32: 47-51$.

Eugène, M., H. Archimède, and D. Sauvant. 2004. Quantitative metaanalysis on the effects of defaunation of the rumen on growth, intake and digestion in ruminants. Livest. Prod. Sci. 85:8581-8597.

Faciola, A. P. and G. A. Broderick. 2014. Effects of feeding lauric acid or coconut oil on ruminal protozoa numbers, fermentation pattern, digestion, omasal nutrient flow, and milk production in dairy cows. J. Dairy Sci. 97:5088-5100.

Grainger, C., and K. A. Beauchemin. 2011. Can enteric methane emissions from ruminants be lowered without lowering their production? Anim. Feed Sci. Technol. 166-167:308-320.

Guan, H., K. M. Wittenberg, K. H. Ominski, and D. O. Krause. 2006. Efficacy of ionophores in cattle for mitigation of enteric methane. J. Anim. Sci. 84:1896-1906.

Hatew, B., S. C. Podesta, H. van Laar, W. F. Pellikaan, J. L. Ellis, J. Dijkstra, and A. Bannink. 2015. Effects of dietary starch content and rate of fermentation on methane production in lactating dairy cows. J. Dairy Sci. 98:486-499.

Hristov, A. N., C. Lee, T. Cassidy, M. Long, K. Heyler, B. Corl, and R. Forster. 2011. Effects of lauric and myristic acids on ruminal fermentation, production, and milk fatty acid composition in lactating dairy cows. J. Dairy Sci. 94:382-395

ISO. 2004. NEN-EN-ISO 1735:2004. Cheese and processed cheese products-Determination of fat content-Gravimetric method (reference method). International Standards Organization, Geneva, Switzerland.

Kil, D. Y., T. E. Sauber, D. B. Jones, and H. H. Stein. 2010. Effect of the form of dietary fat and the concentration of dietary neutra detergent fiber on ileal and total tract endogenous losses and apparent and true digestibility of fat by growing pigs. J. Anim. Sci. 88:2959-2967.

Klop, G., B. Hatew, A. Bannink, and J. Dijkstra. 2016. Feeding nitrate and docosahexaenoic acid affects enteric methane production and milk fatty acid composition in lactating dairy cows. J. Dairy Sci. 99:1161-1172

Klop, G., S. van Laar-van Schuppen, W. F. Pellikaan, W. H. Hendriks, A. Bannink, and J. Dijkstra. 2017. Changes in in vitro gas and methane production from rumen fluid from dairy cows during adaptation to feed additives in vivo. Animal https://doi. org $/ 10.1017 /$ S1751731116002019

Külling, D. R., F. Dohme, H. Menzi, F. Sutter, P. Lischer, and M. Kreuzer. 2002. Methane emissions of differently fed dairy cows and corresponding methane and nitrogen emissions from their manure during storage. Environ. Monit. Assess. 79:129-150.

Martin, C., D. P. Morgavi, and M. Doreau. 2010. Methane mitigation in ruminants: From microbe to the farm scale. Animal 4:351-365.

Rabiee, A. R., K. Breinhild, W. Scott, H. M. Golder, E. Block, and I. J. Lean. 2012. Effect of fat additions to diets of dairy cattle on milk production and components: A meta-analysis and metaregression. J. Dairy Sci. 95:3225-3247.

Santos, M. B., P. H. Robinson, P. Williams, and R. Losa. 2010. Effects of addition of an essential oil complex to the diet of lactating dairy cows on whole tract nutrient digestion and productive performance. Anim. Feed Sci. Technol. 157:64-71. 
Stoop, W. M., H. Bovenhuis, J. M. L. Heck, and J. A. M. van Arendonk. 2009. Effect of lactation stage and energy status on milk fat composition of Holstein-Friesian cows. J. Dairy Sci. 92:1469-1478.

van Gastelen, S., E. C. Antunes-Fernandes, K. A. Hettinga, G. Klop, S. J. J. Alferink, W. H. Hendriks, and J. Dijkstra. 2015. Enteric methane production, rumen volatile fatty acid concentrations, and milk fatty acid composition in lactating Holstein-Friesian cows fed grass silage- or corn silage-based diets. J. Dairy Sci. 98:1915-1927.

van Gastelen, S., and J. Dijkstra. 2016. Prediction of methane emission from lactating dairy cows using milk fatty acids and midinfrared spectroscopy. J. Sci. Food Agric. 96:3963-3968. https:// doi.org/10.1002/jsfa.7718.

van Zijderveld, S. M., B. Fonken, J. Dijkstra, W. J. J. Gerrits, H. B. Perdok, W. Fokkink, and J. R. Newbold. 2011. Effects of a combination of feed additives on methane production, diet digestibility, and animal performance in lactating dairy cows. J. Dairy Sci. 94:1445-1454.
Vlaeminck, B., V. Fievez, A. R. J. Cabrita, A. J. M. Fonseca, and R. J. Dewhurst. 2006. Factors affecting odd- and branched-chain fatty acids in milk: A review. Anim. Feed Sci. Technol. 131:389-417.

Walker, G. P., F. R. Dunshea, and P. T. Doyle. 2004. Effects of nutrition and management on the production and composition of milk fat and protein: A review. Aust. J. Agric. Res. 55:1009-1028.

Yáñez-Ruiz, D. R., A. Bannink, J. Dijkstra, E. Kebreab, D. P. Morgavi, P. O'Kiely, C. K. Reynolds, A. Schwarm, K. J. Shingfield, Z. Yu, and A. N. Hristov. 2016. Design, implementation and interpretation of in vitro batch culture experiments to assess enteric methane mitigation in ruminants-A review. Anim. Feed Sci. Technol. 216:1-18.

Zhou, X., L. Meile, M. Kreuzer, and J. O. Zeitz. 2013. The effect of saturated fatty acids on methanogenesis and cell viability of Methanobrevibacter ruminantium. Archaea 2013:106916. https:// doi.org/10.1155/2013/106916. 